\title{
Synthesis and X-ray crystal structure of a cyclic hemiorthoester
}

\author{
Kerrie A. B. Austin, Martin G. Banwell* and Anthony C. Willis \\ Research School of Chemistry, Australian National University, Canberra, ACT 0200, Australia \\ E-mail:.mgb@,rsc.anu.edu.au
}

\begin{abstract}
Treatment of the acetonides $\mathbf{1}$ and $\mathbf{2}$ with trifluoroacetic acid in the presence of small amounts of water affords, in good yield, the corresponding cyclic hemiorthoesters $\mathbf{5}$ and $\mathbf{6}$, respectively. A single crystal X-ray analysis of compound $\mathbf{5}$ has been carried out.
\end{abstract}

Keywords: Acetonides, anomeric effect, hemiorthoester, hydrolysis, trifluoromethyl group

\section{Introduction}

Hemiorthoesters $\left[\mathrm{R}-\mathrm{C}\left(\mathrm{OR}^{\prime}\right)_{2} \mathrm{OH}\right]$ are the pivotal tetrahedral intermediates associated with acyl transfer reactions including those involved, for example, in the acid-catalyzed esterification of carboxylic acids and in the related trans-esterification processes conducted at $\mathrm{pH}<7$. ${ }^{1}$ The detection of such species and the kinetics associated with their formation and cleavage have been studied extensively and it is clear that the stabilities of these systems varies considerably. ${ }^{2}$ For example, many hemiorthoesters have only been identified as transient intermediates. ${ }^{1,2}$ In certain instances, however, they have proven to be isolable entities and capable of characterization by the standard battery of spectroscopic methods. ${ }^{3}$ This is particularly so when the $\mathrm{R}$ group is a strongly electron-withdrawing one such as $\mathrm{CF}_{3}$ or when the two alcohol residues are linked to one another as seen, for example, in an ethylene glycol or 1,3-propanediol fragment. The impact of the latter construct is highlighted by the remarkable stability of the conjugate base of an hemiorthoester moiety embedded within the dioxaadamantyl core of the marine natural product tetrodotoxin. ${ }^{1}$ Of course, the incorporation of both types of stabilizing groups within the one system leads to compounds of particular stability. Hine and co-workers exploited such possibilities in generating a spectroscopically characterizable hemiorthoester from the monotrifluoroacetate of pinacol. ${ }^{3 a}$ Similarly, reaction of anhydroerythritol with trifluoroacetic anhydride led to the corresponding and crystalline hemiorthoester that was also characterized spectroscopically. ${ }^{3 b}$ Reaction of vicinal diols incorporated within steroidal $^{3 \mathrm{c}}$ and other $^{3 \mathrm{~d}}$ frameworks under the same or related conditions has also led to the isolation of the same types of products. Similarly treatment of certain ring-fused epoxides with trifluoroacetic acid affords 
examples of the title compounds, ${ }^{3 e-g, 4}$ including those incorporated within a $\mathrm{C}_{60}$ framework. ${ }^{3 f, g}$ Despite the efforts outlined above, little structural characterization of hemiorthoesters appears to have been undertaken. Thus, for example, a search of the Cambridge Structural Database (CSD) reveals that, hitherto, only four X-ray crystal structures of hemiorthoesters have been deposited at this site. Three of these are of tetrodotoxin or a derivative ${ }^{5}$ while the fourth involves an example of the title motif embedded within a complex propellane framework that bears an endiyne "strap". 4 Accordingly, we now detail the outcomes of some of our own studies that include the acquisition of a single-crystal X-ray structure of relatively simple hemiorthoester and one that is prepared under rather different reaction conditions to those described previously.

\section{Results and discussion}

In connection with the development of chemoenzymatic total syntheses of various sesquiterpenoid natural products, including the linear triquinanes $(+)$-hirsutene and (-)-complicatic acid, ${ }^{6}$ we prepared the acetonides $\mathbf{1}$ and $\mathbf{2}$ with the intention of converting these, via acid-catalyzed hydrolysis, into the corresponding cis-vicinal diols, viz. 3 and $\mathbf{4}$ respectively. This process proved rather difficult to accomplish under conventional conditions (i.e. using aqueous $\mathrm{HCl}$ in organic solvents such as THF) and prompted an examination of the reaction of compounds 1 and $\mathbf{2}$ with trifluoroacetic acid (TFA) at room temperature and in the presence of small quantities of water. While the formation of the desired diols was indeed observed, these hydrolyses were slow and prompted our running the reactions for extended periods in an effort to achieve higher conversions. However, in each instance, the application of such conditions resulted in the formation of a new, less polar product that became the major one after $72 \mathrm{~h}$. Work-up followed by chromatographic purification of these products led to the isolation of the hemiorthoesters 5 and $\mathbf{6}$ in yields of 87 and 74\%, respectively. Each of these compounds was accompanied by small amounts $(<10 \%)$ of the corresponding acetonides and diols.
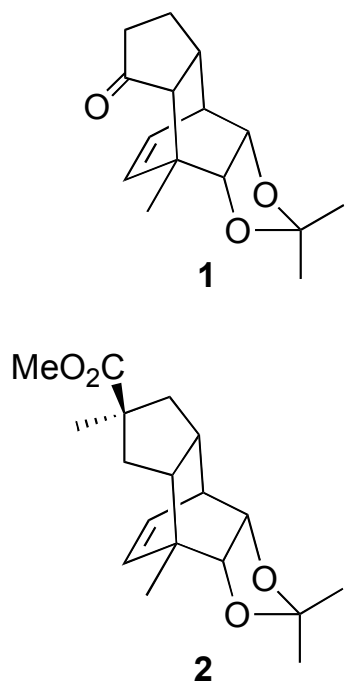
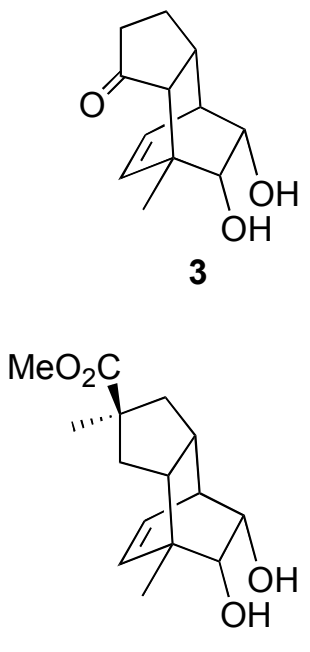

4
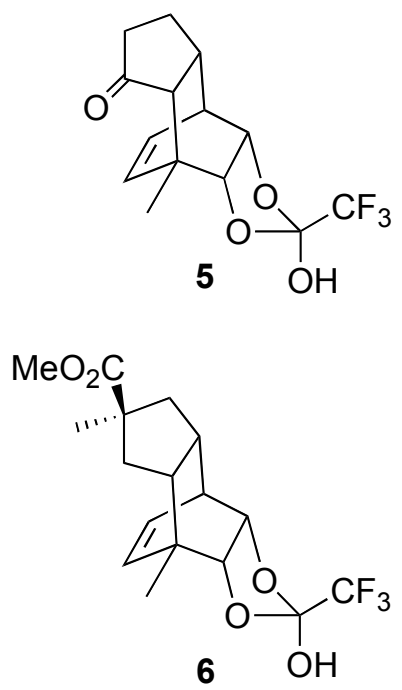
Compounds $\mathbf{5}$ and $\mathbf{6}$ were both obtained in essentially diastereoisomerically pure form and each was subject to various spectroscopic analyses although the slightly unstable nature of the latter one meant that both the ${ }^{1} \mathrm{H}$ and ${ }^{13} \mathrm{C}$ NMR spectra showed the emergence, over time, of signals due to isomeric materials. The $70 \mathrm{eV}$ electron impact mass spectrum of product 5 displayed the expected molecular ion at $\mathrm{m} / z 304$ and an accurate mass measurement on this species established that it had the required composition, viz. $\mathrm{C}_{14} \mathrm{H}_{15} \mathrm{~F}_{3} \mathrm{O}_{4}$. The infrared spectrum revealed a sharp carbonyl stretching band at $1714 \mathrm{~cm}^{-1}$ that is attributed to the annulated cyclopentanone residue on the basis that this same moiety gives rise to an absorption band at $1732 \mathrm{~cm}^{-1}$ in precursor 1 . Since trifluoroacetate-type carbonyl stretching bands appear at $c a$. 1780-1790 $\mathrm{cm}^{-1}$ this suggests that compound 5 does not exist, to any significant extent, in its open-chain/mono-trifluoroacetate ester form. The $300 \mathrm{MHz}{ }^{1} \mathrm{H}$ NMR spectrum of hemiorthoester 5 is entirely consistent with the assigned structure and the oxymethine proton resonances are rather similar to those due the equivalent protons in precursor $\mathbf{1}$, thus suggesting the presence of a 1,3-dioxolane ring in each of these compounds. The $75 \mathrm{MHz}{ }^{13} \mathrm{C}$ NMR spectrum of compound 5 displays twelve of the expected fourteen resonances with those due to the hemiorthoester and $\mathrm{CF}_{3}$-group carbons not being observed. The absence of such signals is ascribed to the slow relaxation times of these nuclei and/or due to ${ }^{13} \mathrm{C}-{ }^{19} \mathrm{~F}$ couplings. Both of these phenomena are likely to lead to low-intensity signals for such carbons. The spectral features just described were also observed for congener 6 . However, definitive evidence in support of the assigned structures 5 and 6 followed from a single-crystal X-ray analysis of the former material (see Figure 1 and Experimental Section) which not only revealed the presence of the cyclic hemiorthoester moiety but also established the exo-orientation of the $\mathrm{CF}_{3}$-group, a feature that is believed to be thermodynamic in origin (vide infra). The lengths of the ring bonds to the hemiorthoester carbon C14 within compound $\mathbf{5}$ are significantly shorter than those associated with their counterparts in a closely related acetonide ${ }^{6 c}$ while they are longer than the equivalent bonds within the single realistically related orthoester found in the CSD. ${ }^{7}$

The conversion of compound $\mathbf{1}$ into the cyclic hemiorthoester $\mathbf{5}$ is presumed to involve initial formation of the TFA conjugate 7 and/or the corresponding regioisomer 8 (Figure 2) which then collapses, with accompanying loss of the elements of acetone, to give the monotrifluoroacetate derivative 9 and/or regioisomer 10. Based on the observations of Hine and others, ${ }^{3 a}$ these mono-trifluoroacetate derivatives of diol $\mathbf{3}$ would be expected to cyclize to give the observed hemiorthoester $\mathbf{5}$ and its epimer but, under the equilibrating conditions likely to be involved, the former and more thermodynamically stable isomer (5) eventually predominates. The anomeric effect is probably responsible for making compound $\mathbf{5}$ more stable than its epimer. Analogous arguments could be invoked to account for the formation of hemiorthoester $\mathbf{6}$ from compound 2. The reversible nature of at least certain of these processes follows from the observation that treatment, at room temperature, of a solution of diol $\mathbf{3}$ in TFA with stoichiometric quantities of acetone affords hemiorthoester 5. Furthermore, and rather surprisingly, simply treating the diol $\mathbf{3}$ with either wet or dry TFA at ambient temperatures also leads to the formation of compound 5. This latter result suggests that TFA is sufficiently 
electrophilic that it can engage in an uncatalyzed esterification reaction with diol 3. This would lead, via one or both of the intermediate mono-esters $\mathbf{9}$ and $\mathbf{1 0}$, to the observed hemiorthoester $\mathbf{5}$. The formation of trifluoroacetates through simple mixing of TFA with alcohols has been observed previously. ${ }^{8}$

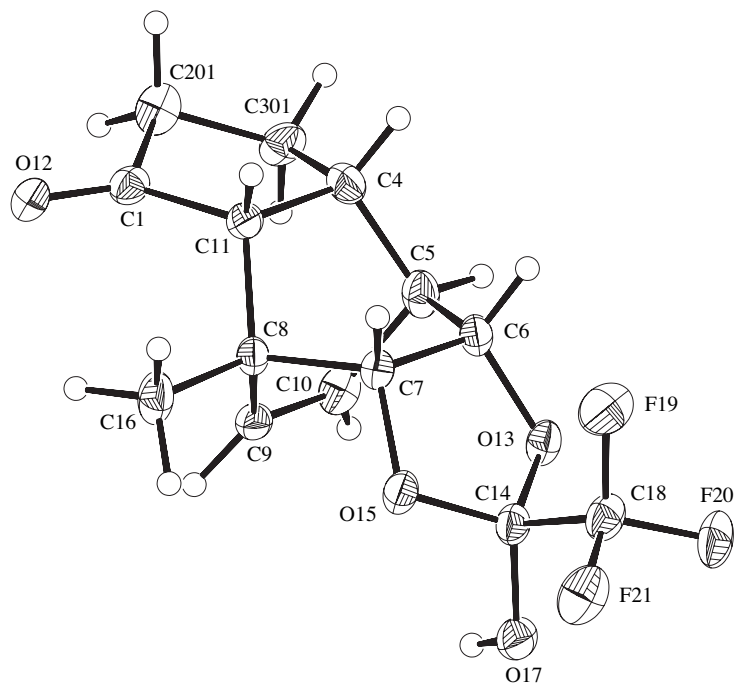

Figure 1. An ORTEP diagram ( $30 \%$ ellipsoids) derived from the single-crystal X-ray analysis of compound 5.

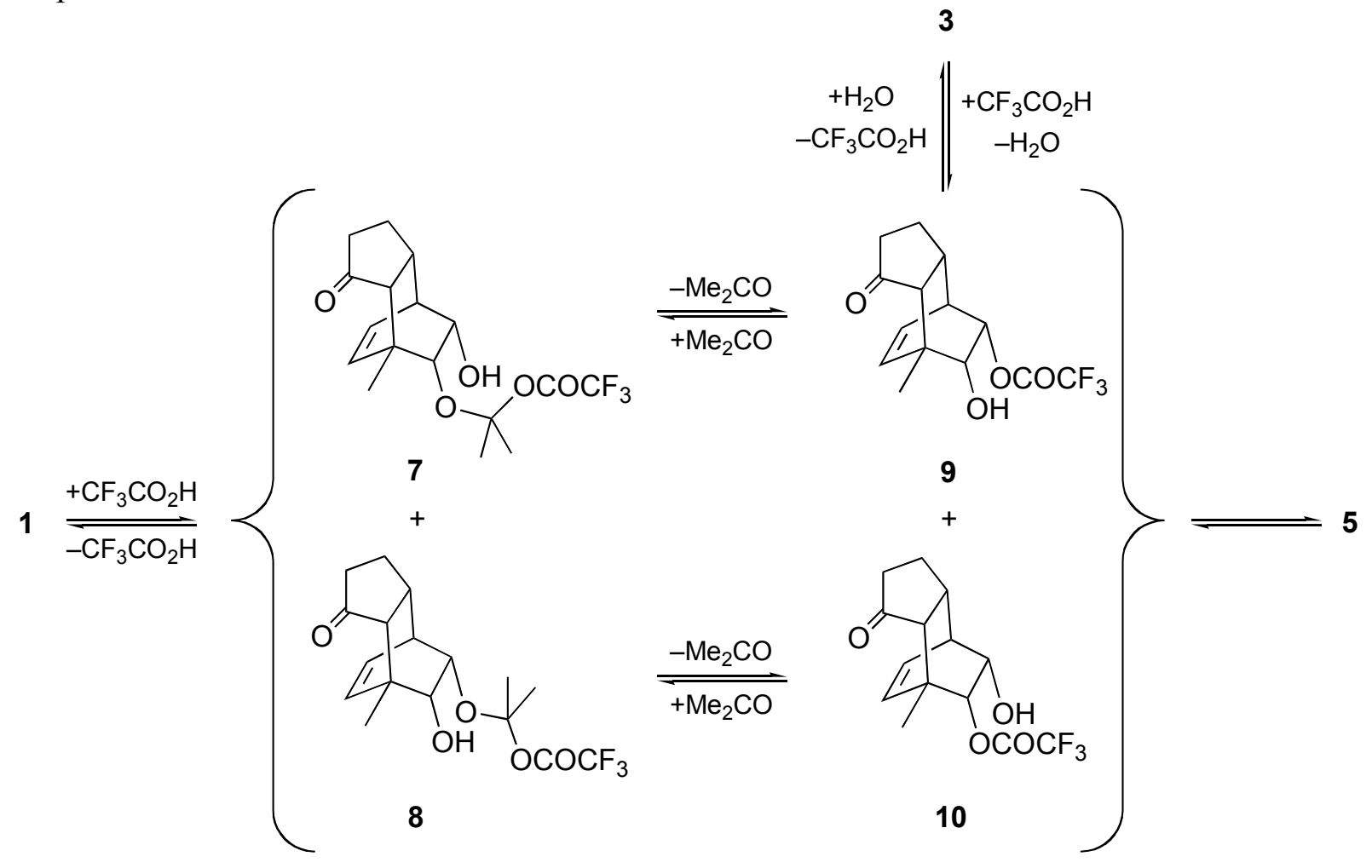

Figure 2. Possible reaction pathways for the interconversions of acetonide 1, diol $\mathbf{3}$ and the hemiorthoester 5. 


\section{Experimental section}

General procedures. Spectral and physical data were recorded as detailed elsewhere. ${ }^{6 a, b}$ Flash chromatography was conducted using the protocols developed by Still et al. ${ }^{9}$

Compound 5. A magnetically stirred solution of acetonide 1 (102 $\mathrm{mg}, 0.41 \mathrm{mmol})$ in TFA (2 $\mathrm{mL}$ ) maintained under nitrogen atmosphere was treated with water (5 drops) and the ensuing mixture stirred at room temperature for 3 days then concentrated under reduced pressure and any residual TFA removed azeotropically using toluene. Subjection of the resulting solid to flash column chromatography (silica gel, $2: 8 \rightarrow 1: 1 \mathrm{v} / \mathrm{v}$ ethyl acetate-hexane gradient elution), afforded three fractions, $\mathrm{A}, \mathrm{B}$ and $\mathrm{C}$.

Concentration of fraction $\mathrm{A}\left[R_{\mathrm{f}}=0.25\right.$ (in $3: 7 \mathrm{v} / \mathrm{v}$ ethyl acetate-hexane)] gave the starting acetonide $\mathbf{1}^{6 \mathrm{c}}$ (4.5 $\mathrm{mg}, 4 \%$ recovery) as a white crystalline solid that was identical, in all respects, with an authentic sample.

Concentration of fraction $\mathrm{B}\left[R_{\mathrm{f}}=0.1\right.$ (in $3: 7 \mathrm{v} / \mathrm{v}$ ethyl acetate-hexane) $]$ afforded a white solid that upon recrystallization $(\mathrm{MeOH})$ gave the hemiorthoester 5 (104 mg, 87\% at $96 \%$ conversion) as a white, crystalline solid, mp $180-181{ }^{\circ} \mathrm{C}$ (Found $\mathrm{M}^{+\bullet}$, 304.0932. $\mathrm{C}_{14} \mathrm{H}_{15} \mathrm{~F}_{3} \mathrm{O}_{4}$ requires $\mathrm{M}^{+\bullet}$, 304.0922; $\Delta=3.1 \mathrm{ppm}) .{ }^{1} \mathrm{H}$ NMR $\left(300 \mathrm{MHz}, \mathrm{CDCl}_{3}\right) \delta 6.32(m, 1 \mathrm{H}), 5.98(d m, J=8.4 \mathrm{~Hz}, 1 \mathrm{H})$, $4.51(d d d, J=7.5,3.3$ and $0.9 \mathrm{~Hz}, 1 \mathrm{H}), 4.07(d d, J=7.5$ and $1.2 \mathrm{~Hz}, 1 \mathrm{H}), 3.26(s, 1 \mathrm{H}), 3.09(m$, 1H), $2.49(m, 1 \mathrm{H}), 2.20-2.00($ complex $m, 3 \mathrm{H}), 1.95(d, J=9.6 \mathrm{~Hz}, 1 \mathrm{H}), 1.70(m, 1 \mathrm{H}), 1.52(s$, $3 \mathrm{H}) ;{ }^{13} \mathrm{C}$ NMR $\left(75 \mathrm{MHz}, \mathrm{CDCl}_{3}\right) \delta 218.2,136.5,131.1,84.6,80.8 .51 .3,42.1,40.6,39.2,35.7$, 24.9, 18.4 (signals due to $\mathrm{CF}_{3}$ and hemiorthoester carbons not observed); IR (neat) $v_{\max } 3118$, 2938, 1714, 1262, 1238, 1174, 1077, 1056, 987, 819, 741, 729, 651; MS (EI) $m / z 304$ (4\%), 149 (38), 148 (100), 120 (55), 106 (90), 105 (73), 92 (85), 91 (65), 56 (70).

Concentration of fraction $\mathrm{C}\left[R_{\mathrm{f}}<<0.1\right.$ (in $3: 7 \mathrm{v} / \mathrm{v}$ ethyl acetate-hexane) $]$ gave diol $3^{6 \mathrm{c}}$ ( $3 \mathrm{mg}, 6 \%$ at $96 \%$ conversion) as a white, crystalline solid that was identical, in all respects, with an authentic sample.

Compound 6. Acetonide $2(122 \mathrm{mg}, 0.39 \mathrm{mmol})$ was treated with TFA/water in the same manner as described above for congener 1. Subjection of the oil obtained on work-up to flash column chromatography (silica gel, $1: 9 \rightarrow 1: 1 \mathrm{v} / \mathrm{v}$ ethyl acetate-hexane gradient elution), afforded three fractions, $\mathrm{A}, \mathrm{B}$ and $\mathrm{C}$.

Concentration of fraction A $\left[R_{\mathrm{f}}=0.5\right.$ (in $3: 7 \mathrm{v} / \mathrm{v}$ ethyl acetate-hexane)] gave the starting acetonide $2^{6 \mathrm{c}}(9.5 \mathrm{mg}, 8 \%$ recovery) as a white crystalline solid that was identical, in all respects, with an authentic sample.

Concentration of fraction $\mathrm{B}\left[R_{\mathrm{f}}=0.3\right.$ (in $3: 7 \mathrm{v} / \mathrm{v}$ ethyl acetate-hexane) $]$ afforded the hemiorthoester 6 (98 $\mathrm{mg}, 74 \%$ at $92 \%$ conversion) as clear, colorless oil (Found $\mathrm{M}^{+*}, 362.1332$. $\mathrm{C}_{17} \mathrm{H}_{21} \mathrm{~F}_{3} \mathrm{O}_{5}$ requires $\left.\mathrm{M}^{+\bullet}, 362.1341 ; \Delta=2.5 \mathrm{ppm}\right) .{ }^{1} \mathrm{H}$ NMR $\left(300 \mathrm{MHz}, \mathrm{CDCl}_{3}\right) \delta 6.21(m, 1 \mathrm{H})$, $5.95(d m, J=8.4 \mathrm{~Hz}, 1 \mathrm{H}), 4.43(d d d, J=7.5,3.3$ and $0.9 \mathrm{~Hz}, 1 \mathrm{H}), 4.04(d d, J=7.5$ and $1.2 \mathrm{~Hz}$, $1 \mathrm{H}), 3.65(\mathrm{~s}, 3 \mathrm{H}), 2.89(\mathrm{~m}, 1 \mathrm{H}), 2.29-2.08$ (complex $m, 3 \mathrm{H}), 1.83(\mathrm{~m}, 1 \mathrm{H}), 1.25(\mathrm{~s}, 1 \mathrm{H}), 1.23(s$, $3 \mathrm{H}), 1.20(s, 3 \mathrm{H}), 1.07-0.92(\mathrm{~m}, 2 \mathrm{H}) ;{ }^{13} \mathrm{C}$ NMR $\left(75 \mathrm{MHz}, \mathrm{CDCl}_{3}\right) \delta 178.1,136.7,131.6,85.4$, 81.7, 52.0, 50.7, 44.6, 41.9, 41.7, 40.3, 39.8, 38.8, 23.7, 19.3 (signals due to $\mathrm{CF}_{3}$ and 
hemiorthoester carbons not observed); IR (neat) $v_{\max } 3401,2962,2932,1728,1712,1463,1378$, 1332, 1298, 1181, 1104, 1075, 1018, 978, 827, 731, 648; MS (EI) m/z 362 (3\%), 303 (23), 206 (95), 174 (78), 159 (68), 146 (100), 131 (85), 105 (63), 101 (69), 91 (69).

Concentration of fraction $\mathrm{C}\left[R_{\mathrm{f}}=0.1\right.$ (in $3: 7 \mathrm{v} / \mathrm{v}$ ethyl acetate-hexane) $]$ gave diol $4^{6 \mathrm{c}}(8 \mathrm{mg}, 7 \%$ at $92 \%$ conversion) as a white, crystalline solid that was identical, in all respects, with an authentic sample.

\section{Crystallographic studies}

Crystal data for compound 5. $\mathrm{C}_{14} \mathrm{H}_{15} \mathrm{~F}_{3} \mathrm{O}_{4}, M=304.26, T=200(1) \mathrm{K}$, monoclinic, space group $P 2_{1}, Z=2, a=7.5275(1), b=12.3444(3), c=7.5910(2) \AA, \beta=106.9743(14)^{\circ}, V=674.65(3)$ $\AA^{3}, D_{x}=1.498 \mathrm{~g} \mathrm{~cm}^{-3}, 1605$ unique data $\left(2 \theta_{\max }=55^{\circ}\right), 1439$ with $I>3.0 \sigma(I) ; R=0.0248, R w=$ $0.0286, S=1.1486$.

Structure determination. Images were measured on a Nonius Kappa CCD diffractometer (MoK $\alpha$, graphite monochromator, $\lambda=0.71073 \AA$ ) and data extracted using the DENZO package. ${ }^{10}$ Structure solution was by direct methods (SIR92). ${ }^{11}$ The structure of compound 5 was refined using the CRYSTALS program package. ${ }^{12}$ Atomic coordinates, bond lengths and angles, and displacement parameters have been deposited at the Cambridge Crystallographic Data Centre (CCDC reference number 607147). These data can be obtained free-of-charge via http://www.ccdc.cam.ac.uk/data_request/cif, by emailing data_request@ccdc.cam.ac.uk, or by contacting The Cambridge Crystallographic Data Centre, 12 Union Road, Cambridge CB2 1EZ, UK; fax: +44 1223336033 .

\section{Acknowledgements}

We thank the Institute of Advanced Studies for financial support and The Australian Government for the award of a PhD Scholarship to KA.

\section{References}

1. For a useful review of this topic see Capon, B.; Gosh, A. K.; Grieve, D. McL. A. Acc. Chem. Res. 1981, 14, 306.

2. See, for example, (a) Guthrie, J. P. Can. J. Chem. 1977, 55, 3562. (b) Capon, B.; Ghosh, A. K. J. Am. Chem. Soc. 1981, 103, 1765. (c) McClelland, R. A.; Patel, G. J. Am. Chem. Soc. 1981, 103, 6908 and 6912. (d) Santry, L. J.; McClelland, R. A. J. Am. Chem. Soc. 1983, 105, 6138. (e) Capon, B.; De Nazar De Matos Sanchez, M. Tetrahedron 1983, 39, 4143. (f) McClelland, R. A.; Seaman, N. E. Can. J. Chem. 1984, 62, 1608. (g) McClelland, R. A. J. Am. Chem. Soc. 1984, 106, 7579. (h) Capon, B.; Dosunmu, M. I. Tetrahedron 1984, 40, 3625. For seminal papers describing stereoelectronic aspects of the reactions of 
hemiorthoesters see: (i) Deslongchamps, P.; Chênevert, R.; Taillefer, R. J.; Moreau, C.; Saunders, J. K. Can. J. Chem. 1975, 53, 1601 and references cited therein.

3. (a) Hine, J.; Ricard, D.; Perz, R. J. Org. Chem. 1973, 38, 110. (b) Bladon, P.; Forrest, G. C. J. Chem. Soc., Chem. Commun. 1966, 481. (c) Galyautdinov, I. V.; Nazmeeva, S. R.; Savchenko, R. G.; Ves'kina, N. A.; Nedopekin, D. V.; Fatykhov, A. A.; Khalilov, L. M.; Odinokov, V. N. Russ. J. Org. Chem. 2004, 40, 675. (d) Pegg, N. A.; Paquette, L. A. J. Org. Chem. 1991, 56, 2461. (e) Hart, H.; Chem, S.-M.; Lee, S. J. Org. Chem. 1980, 45, 2096. (f) Yoshida, M.; Morinaga, Y.; Iyoda, M.; Kikuchi, K.; Ikemoto, I.; Achiba, Y. Tetrahedron Lett. 1993, 34, 7629. (g) Huang, S.; Xiao, Z.; Wang, F.; Gan, L.; Zhang, X.; Hu, X.; Zhang, S.; Lu, M.; Pan, Q.; Xu, L. J. Org. Chem. 2004, 69, 2442.

4. Elbaum, D.; Porco, J. A., Jr.; Stout, T. J.; Clardy, J.; Schreiber, S. L. J. Am. Chem. Soc. 1995, 117, 211.

5. (a) Woodward, R. B.; Gougoutas, J. Z. J. Am. Chem. Soc. 1964, 86, 5030. (b) Tamura, C.; Amakasu, O.; Sasada, Y.; Tsuda, K. Acta Crystallogrt. 1966, 21, 226. (c) Furusaki, A.; Tomiie, Y.; Nitta, I. Bull. Chem. Soc. Jpn. 1970, 43, 3332.

6. (a) Banwell, M. G.; Edwards, A. J.; Harfoot, G. J.; Jolliffe, K. A. Tetrahedron 2004, 60, 535. (b) Banwell, M. G.; Harfoot, G. J. Aust. J. Chem. 2004, 57, 895. (c) Austin, K.; Banwell, M. G.; Harfoot, G. J.; Willis, A. C. Tetrahedron Lett., submitted for publication.

7. Wo, S.; Zieger, H. E.; Millar, M. M.; Koch, S. A. J. Org. Chem. 1995, 60, 5925.

8. (a) Hagen, A. P.; Miller, T. S.; Bynum, R. L.; Kapila, V. P. J. Org. Chem. 1982, 47, 1345.

(b) Samanen, J. M.; Brandeis, E. J. Org. Chem. 1988, 53, 561.

9. Still, W.C.; Kahn, M.; Mitra, A. J. Org. Chem. 1978, 43, 2923.

10. DENZO-SMN. Otwinowski, Z.; Minor, W. Processing of X-ray diffraction data collected in oscillation mode. In Methods in Enzymology, Volume 276: Macromolecular Crystallography, Part A; Carter, C. W., Jr., Sweets, R. M., Eds.; Academic Press: New York, 1997; pp. 307-326.

11. Altomare, A.; Cascarano, G.; Giacovazzo, C.; Guagliardi, A.; Burla, M. C.; Polidori, G.; Camalli, M. J. Appl. Crystallogr. 1994, 27, 435.

12. Betteridge, P. W.; Carruthers, J. R.; Cooper, R. I.; Prout, K.; Watkin, D. J. J. Appl. Crystallogr. 2003, 36, 1487. 